\title{
Avaliação de ultrafiltração como alternativa à flotação por ar dissolvido no pós-tratamento do efluente de lodos ativados - estudo em escala piloto na estação de tratamento de esgoto Brasilia norte
}

\author{
Evaluation of ultrafiltration as an alternative to dissolved air flotation for the \\ post-treatment of activated sludge effluent - pilot study in the Brasilia norte \\ wastewater treatment plant
}

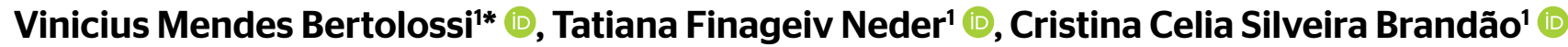

\section{RESUMO}

A melhoria da qualidade dos efluentes das estações de tratamento de esgotos Brasilia Norte e Sul tornou-se premente após o corpo receptor dos seus efluentes, o lago Paranoá, passar a ser utilizado como manancial de abastecimento. Este trabalho apresenta estudo comparativo entre o tratamento terciário por ultrafiltração precedido por coagulação em escala piloto e a flotação por ar dissolvido existente na estação de tratamento de esgotos Brasília Norte. A instalação piloto de ultrafiltração e a flotação por ar dissolvido foram alimentadas pela mesma matriz, o efluente da etapa de lodos ativados das estações de tratamento de esgotos Brasilia Norte, após coagulação. Foram avaliadas sete condições operacionais da instalação piloto de ultrafiltração variando-se a vazão, o tempo de operação entre limpezas e a duração da limpeza física. O comportamento operacional e a qualidade do efluente produzido foram monitorados. O aumento do fluxo do permeado (de 40,2 para 50,6 e 61,0 L.m².h'1) e do tempo de operação entre as limpezas (de 25 para 38 e 50 min), bem como a redução da duração da retrolavagem (de 80 para 60 e 30 s) resultaram em evolução mais intensa da pressão transmembrana. A ultrafiltração foi mais eficiente do que a flotação por ar dissolvido na remoção de turbidez, sólidos suspensos totais, demanda química de oxigênio e fósforo total, com ganho médio de remoção de 9,4, 13,0, 8,5 e $12,8 \%$, respectivamente. Destaca-se a remoção de coliformes na ultrafiltração, 3,4 log superior à da flotação por ar dissolvido. A utilização da ultrafiltração como alternativa à flotação por ar dissolvido apresenta a vantagem de produzir efluente de melhor qualidade, particularmente no aspecto microbiológico, com menor flutuação da qualidade, porém o tratamento e a destinação do lodo produzido pela ultrafiltração devem ser equacionados

Palavras-chave: ultrafiltração; lodos ativados; coagulação; efluente terciário; flotação por ar dissolvido; estações de tratamento de esgotos.

\begin{abstract}
Improvement in the effluent quality of the Brasilia Norte and Brasilia Sul wastewater treatment plants became necessary after their effluent receiving body, Paranoá Lake, started being used as source of drinking water for the population of Brasilia (Federal District, Brazil). This is a comparative study between the tertiary treatment with ultrafiltration membrane (pilot scale) and the existing dissolved air flotation of Brasilia Norte wastewater treatment plant. Both ultrafiltration pilot plant and dissolved air flotation were fed with the same matrix, the effluent of the activated sludge stage of Brasilia Norte wastewater treatment plants, after coagulation. Seven operational conditions were evaluated at ultrafiltration pilot plant, with variations in flow rate, time of operation between cleaning processes, and the duration of backwashing The operational behavior and the quality of the produced effluent were monitored. The increase in permeate flux (from 40.2 to 50.6 and $61.0 \mathrm{~L} . \mathrm{m}^{2} \cdot \mathrm{h}^{\mathrm{A}}$ ) and in the time of operation between cleaning processes (from 25 to 38 and 50 min), as well as the reduction of backwashing duration (from 80 to 60 and 30s). resulted in a more intense evolution of transmembrane pressure. Ultrafiltration was more efficient than dissolved air flotation in the removal of turbidity, total suspended solids, chemical oxygen demand, and total phosphorous, with average gain in removal of $9.4,13.0,8.5$, and $12.8 \%$, respectively. It is worth mentioning the removal of coliforms by ultrafiltration, which was, on average 3.4 log higher than that by dissolved air flotation. The use of ultrafiltration as an alternative to dissolved air flotation has the advantage of producing better quality effluent, particularly regarding microbiological aspects, providing lower quality fluctuation; however, treatment and destination of the ultrafiltration waste must be considered.
\end{abstract}

Keywords: ultrafiltration; activated sludge; tertiary effluent; coagulation; dissolved air flotation; wastewater treatment plant 


\section{INTRODUÇÃO}

De acordo com o relatório publicado pelo Grand View Research em 2020, o mercado de tecnologias de separação por membrana foi estimado em U\$17,9 bilhões em 2019, em comparação a U\$13,3 bilhões em 2016. O relatório atribui esse crescimento à popularização do uso de membranas no campo do saneamento ao longo dos últimos anos, resultado da evolução das tecnologias de fabricação, da redução dos custos e insumos envolvidos e do aumento das restrições legais relativas tanto aos padrões de qualidade da água para consumo humano como ao lançamento de esgotos e ao enquadramento de corpos receptores. O objetivo principal do uso das membranas é a melhoria na qualidade final do produto desejado, seja água para consumo humano (MIERZWA et al., 2012), seja efluente tratado para lançamento em corpo receptor (ZHENG et al., 2012), ou reúso, que se tem tornado prática comum em razão do aumento da demanda por água de qualidade e escassez hídrica em diversos locais do mundo (LEIKNES, 2006).

No caso de Brasília, o Lago Paranoá foi idealizado e construído em 1959, considerando diversos usos da água: complemento paisagístico da cidade, vetor de lazer, geração de energia e diluição dos efluentes secundários de duas estações de tratamento de esgotos (ETE), Brasília Sul (ETEB Sul) e Brasília Norte (ETEB Norte), inauguradas na década de 1960 (CAESB, 2014). Contudo, as soluções de esgotamento sanitário e de tratamento de esgotos (lodos ativados convencionais) adotadas no começo da ocupação do Distrito Federal (DF) não foram suficientes para garantir a preservação da qualidade da água do Lago Paranoá. Com isso, Brasília testemunhou sérios problemas de eutrofização do Lago Paranoá nas décadas de 1970 e 1980 em função do elevado aporte de nutrientes oriundos das duas ETE (ABBT-BRAUN et al., 2014; CAESB, 2014).

Em resposta à situação de degradação, como parte do Programa de Despoluição da Bacia do Lago Paranoá, na década de 1990, as ETE Brasília Sul e Norte foram ampliadas e modernizadas com a adoção do tratamento por lodos ativados modificado (Bardenpho) e da etapa de polimento final com coagulação, floculação seguida de flotação por ar dissolvido (FAD), com vistas à remoção de nutrientes (ABBT-BRAUN et al., 2014). As novas ETE Sul e Norte começaram a operar em 1993 e 1994, respectivamente.

Com a progressiva recuperação, em 2009, o Lago Paranoá tornou-se uma alternativa viável de manancial de água para abastecimento humano no DF e a Companhia de Saneamento Ambiental do DF (Caesb) obteve outorga para captar $2.800 \mathrm{~L} . \mathrm{s}^{-1}$ de água para alimentar uma estação de tratamento de água convencional. Entretanto, diante da crise hídrica que afetou o DF entre 2015 e 2018, foram construídos, em caráter emergencial, dois novos sistemas de captação de água na bacia do Lago Paranoá. No sistema que capta água bruta diretamente do Lago Paranoá, foi implantado, em outubro de 2017, o tratamento por membranas de ultrafiltração (UF) com vazão de $700 \mathrm{~L} \cdot \mathrm{s}^{-1}$.

Com esse novo cenário de utilização do Lago Paranoá como manancial de abastecimento, é premente a necessidade de estudos para avaliar a qualidade dos esgotos tratados lançados no lago, a capacidade de diluição e autodepuração do lago, bem como alternativas para aumentar a eficiência de remoção das ETE Brasília Norte e Brasília Sul (somatório das vazões médias de

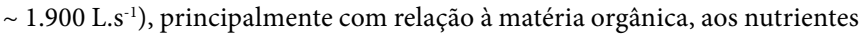
(fósforo e nitrogênio) e aos patógenos.

A utilização de UF no pós-tratamento de efluentes de lodos ativados tem-se mostrado eficiente. Arika et al. (1977), Abdessemed et al. (1999) e Arévalo et al. (2009) obtiveram baixas concentrações de turbidez, de sólidos suspensos totais e de coliformes no permeado da UF que tratou efluentes secundários não coagulados. Vale citar os valores de 0,1 UT para turbidez e 2 NMP/100 $\mathrm{mL}$ para coliformes fecais obtidos por Citulski et al. (2009).

Todavia, a formação do fouling continua sendo o maior desafio e fonte de custo no que tange à operação com membranas (ZHENG et al., 2012), principalmente no tratamento de efluentes secundários, uma vez que a concentração de biopolímeros, maiores causadores de fouling, é elevada (ZHENG et al., 2008). Nesse sentido, a pré-coagulação tem-se apresentado como alternativa para reduzir e controlar a taxa de formação de fouling irreversível na superfície das membranas, uma vez que, ao favorecer o mecanismo de fouling por formação de torta, tende a reduzir a resistência hidráulica da torta (DIAZ et al., 2012; ZHAO et al., 2019, ZHENG et al., 2008). A adoção de etapa de coagulação antecedendo a UF também contribui para o aumento da eficiência de remoção de partículas coloidais e substâncias dissolvidas, como biopolímeros e nutrientes (ZHAO et al., 2019, ZHENG et al., 2012).

Zheng et al. (2012) e Acero et al. (2016), entre outros, constataram que a adoção da coagulação antecedendo a UF resultava em melhora significativa na remoção de fósforo total $\left(<0,05 \mathrm{mg} \cdot \mathrm{L}^{-1}\right)$, ortofosfato $\left(<0,01 \mathrm{mg} \cdot \mathrm{L}^{-1}\right)$, demanda química de oxigênio (DQO) e nitrogênio orgânico (acompanhando a remoção de matéria orgânica). Além disso, em comparação ao processo sem pré-coagulação, o uso de coagulante ( $\mathrm{PAC}, \mathrm{FeCl}_{3}$ e $\mathrm{AlCl}_{3}$ ) promoveu melhora no desempenho do fluxo de permeado (aumento da permeabilidade), redução na taxa de evolução da pressão transmembrana (PTM) e, consequentemente, prolongamento do tempo de operação da UF (SHON et al., 2004; ZHENG et al., 2012; LEE et al., 2009; LY et al., 2018; ZHAO et al., 2019; entre outros). Essa melhora no desempenho operacional da membrana está relacionada, principalmente, ao tamanho e à natureza dos flocos, assim como ao mecanismo de fouling predominante com o uso da pré-coagulação, a formação de torta (ZHENG et al., 2012).

Por outro lado, segundo Lee et al. (2009), Huyskens et al. (2012) e Vedavyasan (2016), o uso de dosagens elevadas de coagulantes metálicos pode favorecer a precipitação de hidróxidos metálicos na superfície da membrana, contribuindo para a formação de fouling irreversível e aumentando a compactação e a resistência hidráulica da torta.

Em trabalho recente, Ragio et al. (2020) utilizaram um sistema de membrana de UF, em escala de bancada, para tratamento de efluentes de reatores anaeróbios com pré-coagulação, e o efeito negativo do uso de dosagens elevadas não foi observado. Os autores concluíram que o aumento da dosagem (variando entre 0, 20, 150 e $\left.950 \mathrm{mg} \mathrm{Al}\left(\mathrm{SO}_{4}\right)_{3} \mathrm{~L}^{-1}\right)$ resultou na redução do fouling total, especialmente do fouling irreversível.

Nesse contexto, o presente estudo tem a finalidade de avaliar, em termos de qualidade e operacionalidade do sistema de UF, a substituição da unidade de polimento final das ETE Brasília Sul e Norte, que hoje envolve a FAD, por um sistema de membranas de UF precedido de coagulação visando aumentar principalmente a remoção de fósforo, matéria orgânica, sólidos e patógenos.

A avaliação operacional verificou a resposta da instalação piloto de tratamento por membranas de UF (IP-UF) quanto à evolução da PTM e à produção de lodo, variando individualmente o fluxo do permeado, o tempo de operação entre as limpezas e a duração da retrolavagem.

Além da melhoria da qualidade do efluente final das ETE, com seu impacto positivo na redução dos riscos para a saúde humana e no ecossistema aquático do Lago Paranoá, o uso da UF em substituição à atual etapa 
de polimento final poderá proporcionar maior segurança operacional para as ETE, bem como viabilizar o uso de outras tecnologias complementares, com exigências de qualidade afluente com maior restrição e regularidade, voltadas para a remoção de micropoluentes emergentes.

\section{METODOLOGIA}

O trabalho, de caráter experimental, foi desenvolvido utilizando unidade piloto de UF instalada na ETEB Norte, localizada as margens do lago Paranoá (WGS 84: 1544’41”S e 4752’42”O), em Brasília, DF, Brasil.

\section{Estação de tratamento de esgoto Brasília Norte}

A ETEB Norte, operada pela (Caesb) do DF, foi projetada para atender uma população de 250 mil habitantes e uma vazão média de 920 L.s ${ }^{-1}$. A ETE utiliza o processo de tratamento por lodos ativados modificado, com remoção de nutrientes (Bardenpho modificado - "luxury uptake"), seguido de polimento final físico-químico, composto de coagulação, floculação e FAD (CAESB/ SEEBLA, 1982; CAESB, 2014). As concentrações dos principais parâmetros de monitoramento da ETEB Norte são apresentadas na Tabela 1.

A ETEB Norte possui um sistema de equalização de vazões dos esgotos brutos que limita os picos normais de variação de vazão diária (CAESB, 2014). O volume estocado retorna ao processo principal (preliminar) nos horários de baixa carga hidráulica.

\section{Etapa de flotação por ar dissolvido na estação de tratamento de esgoto Brasília Norte}

Em sequência aos processos biológicos, a etapa final do tratamento da fase líquida na ETEB Norte ocorre na unidade de polimento final, composta das etapas de mistura rápida, floculação e FAD sob pressão.
A mistura rápida (coagulação) é realizada aproveitando o ressalto hidráulico do medidor de vazão tipo calha Parshall posicionada no canal que reúne os efluentes dos decantadores secundários (DS). O coagulante utilizado é o sulfato de alumínio. A etapa de floculação é constituída de seis unidades mecanizadas operadas em paralelo. Cada unidade de floculação é composta de duas câmaras em série; na primeira o gradiente de velocidade (G) é de 100 $\mathrm{s}^{-1}$, enquanto na segunda é de $60 \mathrm{~s}^{-1}$. O tempo de detenção total é estimado em cerca de 15 minutos.

A etapa de FAD, com recirculação e pressurização de parte do efluente final, é composta de seis câmaras de flotação. $\mathrm{O}$ ar comprimido é fornecido por dois compressores e a recirculação de efluente saturado com ar é distribuída para cada câmara de flotação através de um manifold. A escuma flotada é removida por raspadores superficiais e encaminhada para a etapa de desidratação de lodo. A taxa de aplicação superficial (3,6 a $\left.15 \mathrm{~m}^{3} \mathrm{~m}^{-2} \mathrm{~h}^{-1}\right)$, assim como a relação ar/sólido (0,016 a 0,066 g ar/g sólido), varia em função da vazão de operação.

\section{Instalação piloto de tratamento por membranas de ultrafiltração}

A IP-UF foi projetada e fabricada em 2011 pela DOW Water and Process Solutions. É montada em um contêiner, possui um sistema completo e automatizado de tratamento por membranas de UF, opera com fluxo constante frontal (dead-end de fora para dentro) e pressão de alimentação variável. A Figura 1 apresenta o fluxograma simplificado da IP-UF.

A membrana de UF utilizada na instalação piloto foi a IntegraFlux SFP 2880XP da empresa DOW Water and Process Solutions (atualmente parte do grupo DuPont Water Solutions). A Tabela 2 apresenta as principais características do módulo da membrana de UF da IP-UF. Embora no arranjo original da IP-UF exista o pré-filtro de disco de polipropileno de $200 \mathrm{~mm}$, neste trabalho ele não foi utilizado.

Tabela 1 - Mediana das concentrações e eficiência de remoção dos principais parâmetros de monitoramento da estação de tratamento de esgoto Brasília Norte para o período de 2016 a 2018.

\begin{tabular}{|c|c|c|c|c|c|}
\hline Ano 2016 a 2018 & Afluente & $\begin{array}{l}\text { Afluente aos } \\
\text { reatores biológicos }\end{array}$ & $\begin{array}{c}\text { Afluente ao } \\
\text { polimento final }\end{array}$ & Efluente final & $\begin{array}{l}\text { Eficiência de } \\
\text { remoção total (\%) }\end{array}$ \\
\hline Alcalinidade total (mg.L'1) & 222 & - & 72 & - & - \\
\hline $\mathrm{pH}$ & 7,4 & 7,4 & 7,2 & 7,2 & - \\
\hline Turbidez (UTN) & - & 122,0 & 12,6 & 2,3 & - \\
\hline $\mathrm{SST}\left(\mathrm{mg} \cdot \mathrm{L}^{-1}\right)$ & 254 & 124 & 27 & 6,8 & 97,3 \\
\hline $\mathrm{DBO}\left(\mathrm{mg} \cdot \mathrm{L}^{-1}\right)$ & 400 & - & - & 5 & 98,8 \\
\hline $\mathrm{DQO}\left(\mathrm{mg} \cdot \mathrm{L}^{-1}\right)$ & 631,0 & 459,0 & 70,0 & 37,3 & 94,1 \\
\hline DQOf (mg. L'1) $\left.^{-1}\right)$ & - & - & 40,0 & 32,0 & - \\
\hline $\mathrm{N}-\mathrm{NH}_{3}\left(\mathrm{mg} \cdot \mathrm{L}^{-1}\right)$ & - & - & 13,4 & 13,3 & - \\
\hline Nitrogênio total (mg.L-1') & 64 & - & - & 18 & 71,9 \\
\hline Fósforo total (mg.L') & 7,40 & 8,40 & 1,95 & 0,23 & 96,9 \\
\hline Coli. totais (NMP/100mL) & $2,0 \mathrm{E}+\mathrm{O} 7$ & - & - & $6,0 \mathrm{E}+\mathrm{O} 4$ & 99,7000 \\
\hline E. Coli (NMP/100mL) & 1,3 E+O7 & - & - & $9,8 E+04$ & 99,2457 \\
\hline
\end{tabular}

SST: sólidos suspensos totais; DBO: demanda bioquímica de oxigênio; DQO: demanda química de oxigênio; DQOf: demanda química de oxigênio filtrada; N-NH: nitrogênio de amônia; Coli. totais: coliformes totais; E. Coli: Escherichia Coli.

Fonte: CAESB, 2019 
A IP-UF era alimentada com os efluentes dos DS do sistema de lodos ativados da ETEB Norte. A captação era realizada, por meio de bombeamento, no canal que transportava água efluente dos DS para o sistema de polimento final, em ponto a jusante da calha Parshall, onde ocorria a aplicação do coagulante. Dessa forma, a alimentação da IP-UF era a mesma do sistema de FAD, o que permitiu a comparação da eficiência de remoção de fósforo e de outros parâmetros entre a FAD em escala real e a UF em escala piloto.

\section{Condições operacionais}

Considerando que a IP-UF utilizava um módulo comercial de membrana, para a definição das condições operacionais a serem avaliadas no trabalho, optou-se pela utilização do software Water Application Value Engine (WAVE) adotado pelo fabricante para o dimensionamento e a otimização de instalações em escala real. Esse software incorpora modelos teóricos de fluxo, características da membrana e características do efluente para produzir informações de projeto, operação e desempenho da membrana. Assim, para a qualidade do efluente que seria tratado (Tabela 1) na IP-UF e o modelo da membrana instalada na IP-UF (Tabela 2), foi obtida, utilizando o software, a condição operacional recomendada. Essa condição, mostrada na Tabela 3, foi considerada referencial (condição padrão - P) para a definição das demais condições operacionais avaliadas neste trabalho (Tabela 4 ).

Dessa forma, o desempenho da instalação piloto de UF foi avaliado na condição operacional padrão descrita na Tabela 3, bem como em outras seis condições nas quais diferentes parâmetros operacionais foram variados, a saber: vazão de permeado e, consequentemente, fluxo de permeado, já que a área de membrana é constante; tempo de operação entre limpezas; e duração da retrolavagem (tempo de limpeza física). Como pode ser observado na Tabela 4, os parâmetros foram variados um a um, mantendo-se os demais parâmetros operacionais constantes com o objetivo de observar o impacto dessas variações no comportamento da PTM e na qualidade do permeado.

Tabela 2 - Principais características do módulo da membrana de ultrafiltração.

\begin{tabular}{l|c} 
Elemento filtrante & IntegraFlux SFP - 2880XP \\
Diâmetro nominal dos poros & $0,03 \mathrm{~mm}$ \\
\hline Diâmetro interno/externo da fibra oca & $0,70 \mathrm{~mm} / 1,30 \mathrm{~mm}$ \\
\hline Material & Fluoreto de polivinilideno hidrofílica \\
\hline Fluxo do filtrado a $25^{\circ} \mathrm{C}$ & 40 a $120 \mathrm{l} \cdot \mathrm{m}^{-2} \cdot \mathrm{h}^{-1}$ \\
\hline Fluxo do filtrado corrigido para $20^{\circ} \mathrm{C}$ & 35,49 a $106,48 \mathrm{l} \cdot \mathrm{m}^{-2} . \mathrm{h}^{-1}$ \\
\hline Número de fibras por módulo & 10.000 \\
\hline Área efetiva da superfície da membrana & $77 \mathrm{~m}^{2}$ \\
\hline
\end{tabular}

A dosagem de coagulante, sulfato de alumínio, era definida pela equipe operaciona da ETEB Norte com base na qualidade do efluente dos decantadores secundários. No período de realização do trabalho a dose média aplicada foi de 97 mg.L', com desvio padrão de $82 \mathrm{mg} \cdot \mathrm{L}^{-1}$.

Fonte: DOW Water \& Process Solution, 2011.

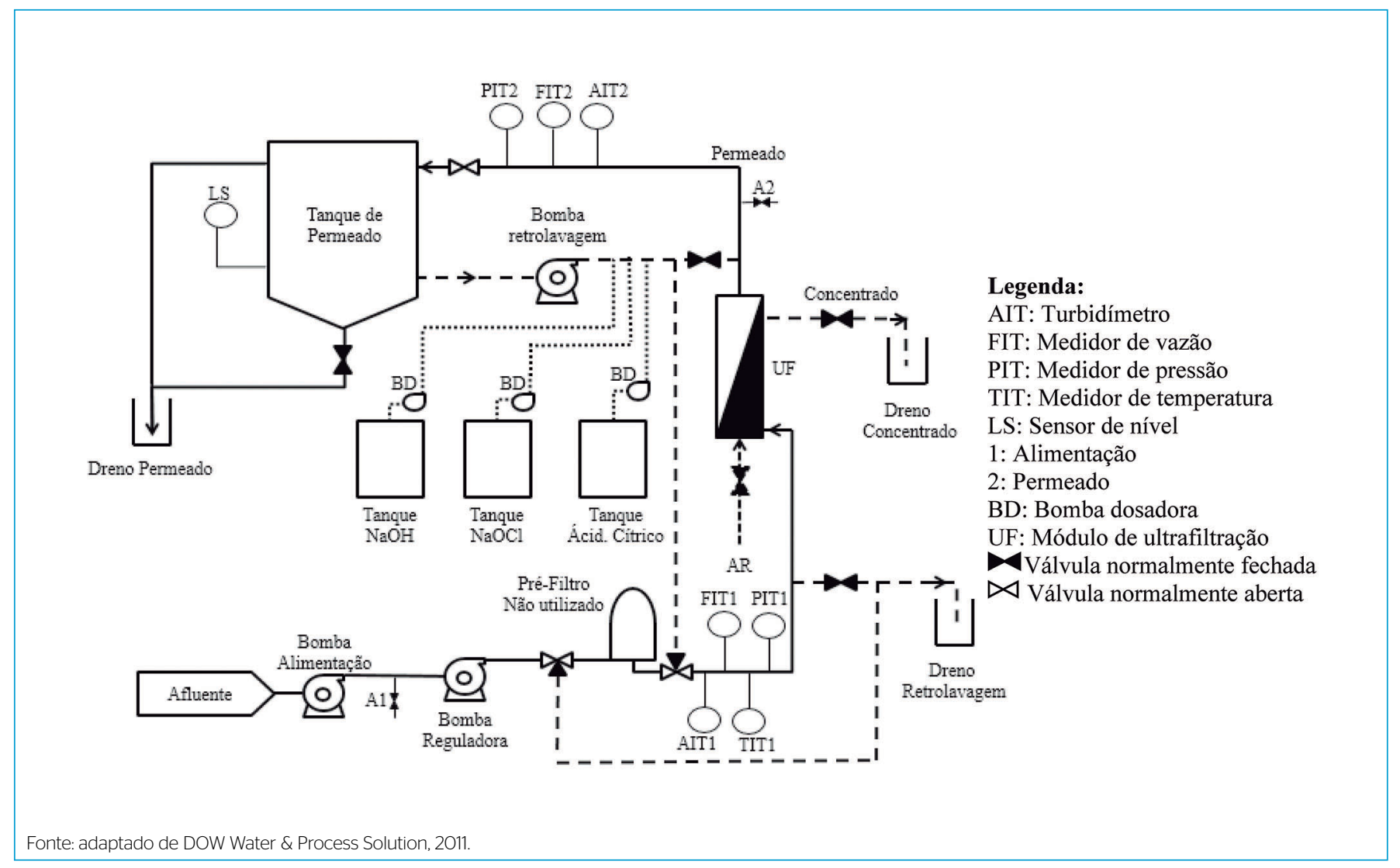

Figura 1 - Fluxograma simplificado da instalação piloto por membrana de ultrafiltração utilizada no desenvolvimento do trabalho. 
Tabela 3 - Parâmetros operacionais de referência obtidos com uso do software Water Application Value Engine, considerando-se a qualidade do esgoto afluente à instalação piloto.

\begin{tabular}{l|c|c}
\hline Processo de filtração & Unidade & Valor \\
\hline Módulo de ultrafiltração & - & IntegraFlux SFP - 2880XP \\
\hline Número de módulos & un & 1 \\
\hline Vazão do permeado a 25ㄷ & $\mathrm{m}^{3} \cdot \mathrm{h}^{-1}$ & 3,1 \\
\hline Fluxo do permeado a $25^{\circ} \mathrm{C}$ & $\mathrm{I} \cdot \mathrm{m}^{2} \mathrm{~h}^{-1}$ & 40,25 \\
\hline Duração da filtração (tempo de operação) & $\mathrm{min}$ & 25 \\
\hline Frequência de retrolavagem & $\mathrm{min}$ & 25 \\
\hline Frequência de CEB 1 & $\mathrm{h}$ & 12 \\
\hline Frequência de CEB 2 & $\mathrm{h}$ & 24 \\
\hline Variação de pressão transmembrana & bar & $0,5 \mathrm{a} 1,2$ \\
\hline
\end{tabular}

CEB: chemically enhanced backwash.

Fonte: elaborada pelos autores.
Para o cálculo do volume de lodo produzido (L) na IP-UF foram considerados os volumes de retrolavagem registrados no supervisório da instalação piloto, acrescidos do volume de drenagem do módulo estimado por limpeza (físicas e químicas) realizada durante cada experimento. O volume de enxágue não foi contabilizado no lodo, já que é realizado como próprio afluente à membrana.

\section{Parâmetros de qualidade}

Os parâmetros de qualidade avaliados no afluente à IP-UF (que é também afluente ao sistema de FAD) e seu permeado, bem como no efluente da FAD (o efluente final da ETEB Norte) e suas respetivas frequências de monitoramento, são apresentados na Tabela 5.

O tipo de amostragem nos pontos de coleta foi composta de alíquotas obtidas de hora em hora, durante 4 horas, das $8 \mathrm{~h}$ às $12 \mathrm{~h}$, em dias determinados. As análises foram realizadas no Laboratório Central da Caesb e no laboratório operacional da ETEB Norte utilizando as metodologias do Standard Methods, 23a Edição (APHA, AWWA \& WEF, 2017).

Tabela 4 - Condições operacionais aplicadas na instalação piloto de ultrafiltração.

\begin{tabular}{|c|c|c|c|c|c|c|}
\hline \multirow[b]{2}{*}{ Fase } & \multirow[b]{2}{*}{ Condição avaliada } & \multicolumn{2}{|c|}{ Condições de filtração } & \multirow{2}{*}{$\begin{array}{c}\text { Tempo de } \\
\text { limpeza física (s) }\end{array}$} & \multirow{2}{*}{$\begin{array}{l}\text { Repetição } \\
\text { da fase }\end{array}$} & \multirow[b]{2}{*}{ CEB $1(h)$} \\
\hline & & $\begin{array}{l}\text { Tempo de operação } \\
\text { entre limpezas (min) }\end{array}$ & Vazão / fluxo do permeado & & & \\
\hline 1 & Condição padrão & 25 & $3,1 \mathrm{~m}^{3} \cdot \mathrm{h}^{-1} / 40,25 \mathrm{l} \cdot \mathrm{m}^{-2} \cdot \mathrm{h}^{-1}$ & 60 & 2 & 12 e 12 \\
\hline 2 & \multirow{2}{*}{ Variação da vazão } & 25 & $4,7 m^{3} \cdot h^{-1}(1,5 Q) / 61,04 I \cdot m^{-2} \cdot h^{-1}$ & 60 & 1 & 12 \\
\hline 3 & & 25 & $3,9 m^{3} \cdot h^{-1}(1,25 Q) / 50,65 \mathrm{l} \cdot \mathrm{m}^{-2} \cdot \mathrm{h}^{-1}$ & 60 & 1 & 12 \\
\hline 4 & \multirow{2}{*}{$\begin{array}{l}\text { Variação da duração da retrolavagem - } \\
\text { limpeza física }\end{array}$} & 25 & $3,1 \mathrm{~m}^{3} \cdot \mathrm{h}^{-1} / 40,25 \mathrm{l} \cdot \mathrm{m}^{-2} \cdot \mathrm{h}^{-1}$ & $84(1,4 \mathrm{TL})$ & 1 & 12 \\
\hline 5 & & 25 & $3,1 \mathrm{~m}^{3} \cdot \mathrm{h}^{-1} / 40,25 \mathrm{l} \cdot \mathrm{m}^{-2} \cdot \mathrm{h}^{-1}$ & $30(0,5 T L)$ & 1 & 8 \\
\hline 6 & \multirow{2}{*}{$\begin{array}{c}\text { Variação de tempo de operação } \\
\text { entre limpezas }\end{array}$} & $38(1,5 \mathrm{TO})$ & $3,1 m^{3} \cdot h^{-1} / 40,25$ I.m.2. $h^{-1}$ & 60 & 3 & 7,4 e 12 \\
\hline 7 & & 50 (2TO) & 3,1 $\mathrm{m}^{3} \cdot \mathrm{h}^{-1} / 40,25 \mathrm{l} \cdot \mathrm{m}^{-2} \cdot \mathrm{h}^{-1}$ & 60 & 2 & 5 e 12 \\
\hline
\end{tabular}

Q: vazão; TO: tempo de operação; TL: tempo de limpeza; CEB: chemically enhanced backwash.

Fonte: elaborada pelos autores.

Tabela 5 - Parâmetros e frequência de monitoramento do afluente e permeado da instalação piloto de ultrafiltração e efluente final da estação de tratamento Brasília Norte.

\begin{tabular}{|c|c|}
\hline Parâmetros & Frequência \\
\hline Temperatura do afluente & \multirow{2}{*}{ Medição em linha da IP-UF } \\
\hline Turbidez do permeado & \\
\hline pH e ortofosfato do afluente & \multirow{2}{*}{ Medição em linha da ETEB Norte antes da coagulação } \\
\hline Turbidez do efluente após os decantadores secundários e antes da etapa de coagulação & \\
\hline Turbidez (afluente IP-UF e efluente FAD) & \multirow{7}{*}{$\begin{array}{c}3 \text { vezes por experimento (início, meio e fim do experimento). Obs.: Essa } \\
\text { frequência foi alterada quando a duração do experimento não atingia } \\
\text { o planejado (7 dias) }\end{array}$} \\
\hline $\mathrm{pH}$ & \\
\hline $\begin{array}{l}\text { Sólidos dissolvidos totais (SDT), Sólidos suspensos (SST); Sólidos totais (ST); Sólidos totais voláteis } \\
\text { (STV); Sólidos totais fixos (STF) }\end{array}$ & \\
\hline Demanda química de oxigênio (DQO) e filtrada (DQOf) & \\
\hline Fósforo total (Pt) & \\
\hline Nitrito $\left(\mathrm{NO}_{2}\right)$; Nitrato $\left(\mathrm{NO}_{3}\right)$ e Amônia $\left(\mathrm{NH}_{3}\right)$ & \\
\hline Coliforme totais (CT) e Escherichia Coli (E. Coli) & \\
\hline
\end{tabular}

IP-UF: instalação piloto de tratamento por membranas de ultrafiltração; ETEB Norte: estação de tratamento de esgoto Brasília Norte; FAD: flotação por ar dissolvido. Fonte: elaborada pelos autores. 


\section{RESULTADOS E DISCUSSÃO}

\section{Efeito das condições operacionais na pressão transmembrana}

Os experimentos foram realizados em sete fases (Tabela 4) de modo a analisar a evolução da PTM ao longo deles e comparar os resultados das fases. A Figura 2 demonstra o desenvolvimento da PTM durante a operação da IP-UF. A condição operacional padrão da fase 1 (P) foi considerada referência para comparação dos dados apresentados na Figura 2.

Como esperado, a condição padrão $(\mathrm{P})$ apresentou duração do experimento prolongada e recuperação da PTM inicial após as limpezas químicas, atendendo aos limites de segurança da PTM indicados pelo fabricante (2,1 bar). Com isso, o experimento foi interrompido por atingir o tempo planejado de operação do experimento (sete dias).

Com relação à variação da duração da retrolavagem, Figura 2b, observa-se que na fase $4(1,4 \mathrm{TL}=80 \mathrm{~s})$ ocorreu um desenvolvimento da PTM notadamente menor que a fase $1(\mathrm{P}: \mathrm{TL}=60 \mathrm{~s})$, com o valor de $\mathrm{dPTM} / \mathrm{dT}$ inferior a $30 \%$ da condição padrão, pela maior eficiência dos processos de limpeza física com ar e água. A redução da duração da retrolavagem na fase $5(0,5 \mathrm{TL}=30 \mathrm{~s})$, por outro lado, resultou numa evolução mais intensa da PTM comparada à das outras fases ( 1 e 2), como observado nos valores da dPTM/dT na Figura $2 b$. Como esperado e também observado por Diaz et al. (2012), a relação inversa entre o aumento da duração do tempo da limpeza física (ar e água) da IP-UF e a evolução da PTM também foi notável para as características do efluente do sistema de lodos ativados da ETEB Norte.

Conforme Yoon (2015), o aumento de tempo de operação entre as limpezas provoca, de forma proporcional, a evolução da PTM para manter o fluxo constante, pois a deposição contínua de produtos microbiológicos solúveis e biopolímeros (fouling) provoca uma tendência de redução do fluxo no tempo. Foram confirmadas as expectativas de desenvolvimento da PTM mais intenso para as fases $6(1,5 \mathrm{TO} 3)$ e 7 (2TO 2) comparadas com a fase 1 (P), conforme pode ser observado na Figura 2c. Por outro lado, comparando as fases 6 (1,5TO 3$)$ e 7 (2TO 2), observa-se um comportamento de evolução da PTM (dPTM/dT) semelhante, o que sugere alguma interferência externa à operação da IP-UF.

A Tabela 6 apresenta os resultados de recuperação do módulo de membrana nas diferentes condições operacionais avaliadas. A variação da recuperação r (\%), na faixa de 82,2 a $91,7 \%$, é inversamente relacionada com o volume de retrolavagem utilizado e diretamente relacionada com o volume produzido em um determinado período de tempo.

\section{Aspectos de qualidade}

Como as membranas de UF atuam principalmente por exclusão de tamanho, todos os parâmetros físico-químicos e microbiológicos que estão relacionados com tamanhos de partículas que possuam dimensões maiores que o tamanho dos poros da membrana (turbidez, sólidos suspensos totais - SST, fósforo total $-\mathrm{Pt}$, coliformes totais e Escherichia Coli $-E$. Coli) apresentaram melhores resultados de remoção e de concentração após o tratamento por UF, como pode ser observado na Tabela 7 e na Tabela 8 . A elevada remoção de partículas não dissolvidas no tratamento de efluente de lodos ativados por UF também foi observada por Citulski et al. (2009) e Zheng et al. (2012), assim como por Zhao et al. (2019) e Li et al. (2018) em biorreator por membranas (BRM) usando UF.
Os valores observados para coliformes totais e E. Coli retratam um módulo com uma ocorrência de fibras rompidas com o tempo de operação, visto que, pelo diâmetro nominal dos poros da membrana, não se tinha a expectativa de presença de coliformes no permeado da UF, como relatado por Arika et al. (1977), Abdessemed et al. (1999), Arévalo et al. (2009) e Citulski et al. (2009). O rompimento das fibras foi confirmado no teste de estanqueidade realizado quando se constatou a redução da eficiência de remoção de coliformes. Aqui cabe comentar que as fases não foram realizadas de forma sequencial; as fases 1 e 5 apresentadas na Tabela 8 foram efetuadas antes do teste de estanqueidade, enquanto as fases 3, 6 e 7 foram executadas após a fixação das fibras rompidas. Conforme Metcalf e Eddy (2015), o rompimento de fibras de membranas de UF possui impactos significativos na qualidade do permeado de membranas de UF com relação à quantificação de Escherichia Coli; no entanto, para outros parâmetros, como turbidez, o rompimento das fibras não apresenta impactos significativos na qualidade do permeado

Todas as condições operacionais avaliadas apresentaram remoções elevadas para turbidez, SST, DQO, Pt e E. Coli. Esses parâmetros representam a parte suspensa presente no esgoto com coagulação química, de modo que o bom desempenho da membrana UF era esperado.

Todavia, a comparação entre as alterações de condições de operação das fases do trabalho torna-se complexa e não conclusiva principalmente em virtude da falta de otimização da dosagem de coagulante para o processo de UF (a dosagem era definida em função da necessidade da ETEB Norte), da qualidade afluente à IP-UF não constante e a pequeno número de amostras por experimento (três amostras em sete dias de experimento para cada fase). Vale ressaltar também a influência do erro de métodos de quantificação dos parâmetros que apresentam concentração muito baixa e/ou próxima ao limite de detecção do equipamento, tais como turbidez, SST, E. Coli e coliformes totais.

\section{Avaliação comparativa entre ultrafiltração e flotação por ar dissolvido}

A Tabela 9 apresenta os volumes de rejeito/lodo obtidos durante o processo de limpeza e sua relação com o volume permeado da IP-UF nas diferentes fases experimentais

Na Tabela 9 se pode observar que a relação entre L e volume de efluente $\left(V_{p}-V_{r}\right)$ variou entre 0,11 e $0,33 \mathrm{~m}^{3} \cdot \mathrm{m}^{-3}$, correspondendo ao inverso da variação da recuperação apresentada na Tabela 6 .

A Tabela 10 apresenta a relação entre o volume de lodo químico produzido na etapa de FAD durante o ano de 2018 e o volume de esgoto tratado na ETEB Norte. Como pode ser observado, o valor médio anual dessa relação foi de $0,0022 \mathrm{~m}^{3} \cdot \mathrm{m}^{-3}$, o que corresponde a aproximadamente $1 \%$ do L na IP-UF (média de $0,17 \mathrm{~m}^{3} \cdot \mathrm{m}^{3}$ ). Dessa forma, o volume relativo de lodo químico da IP-UF é cerca de 17 vezes maior que o volume médio relativo de lodo total da ETEB Norte $\left(0,0101 \mathrm{~m}^{3} \cdot \mathrm{m}^{-3}\right)$.

Com a elevada produção de resíduos da IP-UF, deve ser avaliada uma solução para tratamento ou recirculação interna do lodo na própria ETE (para o decantador primário ou reator).

Foram realizadas análises físico-químicas e bacteriológicas representativas para esgotos domésticos de forma a identificar a qualidade do polimento final existente na ETEB Norte (FAD) e a qualidade da IP-UF (Tabela 11). Para isso 

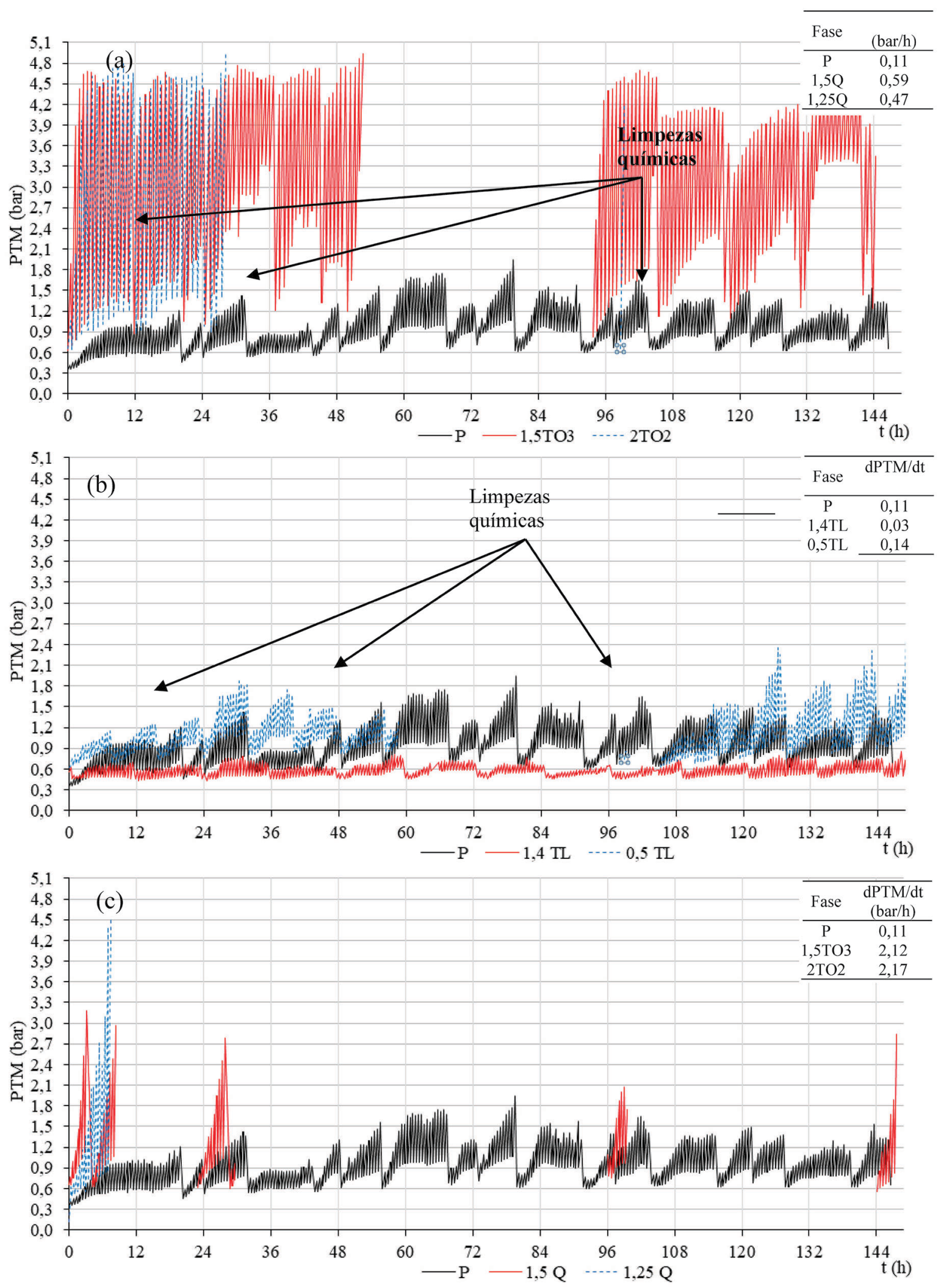

P: condição padrão; vazão do permeado: $Q=3,1 \mathrm{~m}^{3} \mathrm{~h}^{1}$; duração da retrolavagem: $T L=60$ s; vazão do permeado $\mathrm{Q}=3,1 \mathrm{~m}^{3} \mathrm{~h}^{\top 1}$; frequência de limpeza química: alcalina/oxidante $\mathrm{CEB} 1$ = $12 \mathrm{~h}$ e ácida $\mathrm{CEB} 2$ = 24h; dPTM/dT = variação média da pressão transmembrana no tempo.

Fonte: elaborada pelos autores.

Figura 2 - Desenvolvimento da pressão transmembrana com o tempo de operação do experimento (t) para as fases: (a) fase 1 (P), fase $2(1,5 \mathrm{Q})$ e fase $3(1,25 \mathrm{Q})$; (b) fase $1(P)$, fase $4(1,4 T L)$ e fase 5 (0,5TL) e; (c) fase 1 (P), fase 6 - 3a repetição (1,5TO 3) e fase $7-2^{\mathrm{a}}$ repetição (2TO 2). 
foi utilizado o mesmo afluente nos dois sistemas, ou seja, efluente dos DS da etapa de lodos ativados, após coagulação.

Como as membranas de UF são barreiras seletivas por filtração, melhores resultados de remoção e de concentração após o tratamento por UF, quando comparado com a FAD, foram observados para os parâmetros físico-químicos e microbiológicos que estão relacionados com impurezas de dimensões maiores que o tamanho dos poros da membrana. Por outro lado, a membrana de UF, assim como a FAD, não foi efetiva na remoção de substâncias dissolvidas (sólidos dissolvidos totais, $\mathrm{NO}_{2}, \mathrm{NO}_{3}$ e $\mathrm{NH}_{3}$ ), como esperado. Os parâmetros de qualidade que apresentaram concentrações médias mais baixas após o tratamento por UF foram: tur-

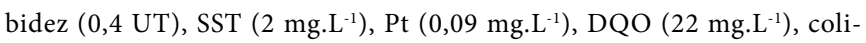
formes totais $(2,0 \mathrm{E}+02 \mathrm{NMP} / 100 \mathrm{ml})$ e E. Coli $(1,2 \mathrm{E}+02 \mathrm{NMP} / 100 \mathrm{ml})$.
Em termos de remoção, comparativamente, destaca-se que, em média, o uso da UF representou ganho de remoção 9,4\% de turbidez, de $13,0 \%$ de SST, de $8,5 \%$ de DQO, de $12,8 \%$ de Pt e mais que 3,4 log de remoção de coliformes. Apesar do excelente resultado obtido com relação à remoção de coliformes na IP-UF ( $>4,3$ log em média), vale comentar que foram detectadas e isoladas na avaliação da integridade das fibras do módulo de membranas cinco fibras rompidas, o que pode ter comprometido a remoção de microrganismos.

Com a expressiva remoção de bactérias do grupo coliformes observada na UF, infere-se que microrganismos de maior dimensão, tais como protozoários, ovos de helminto, cisto de Giardia, (oo)cistos de Cryptosporidium, entre outros, também tenham sido removidos pela membrana de UF. Com relação à remoção de vírus, alguns estudos apontam elevada remoção de vírus em membranas

Tabela 6 - Recuperação do módulo de membrana de ultrafiltração e as fases experimentais.

\begin{tabular}{|c|c|c|c|c|c|c|c|c|c|}
\hline & $\begin{array}{c}\text { Fase } 1 \\
\text { (P) }\end{array}$ & $\begin{array}{c}\text { Fase } 1 \\
(\mathrm{P} 2)\end{array}$ & $\begin{array}{c}\text { Fase } 2 \\
(1,5 \mathrm{Q}) \\
4,7 \mathrm{~m}^{3} \cdot \mathrm{h}^{-1}\end{array}$ & $\begin{array}{c}\text { Fase } 3 \\
(1,25 \mathrm{Q}) \\
3,9 \mathrm{~m}^{3} \cdot \mathrm{h}^{-1}\end{array}$ & $\begin{array}{c}\text { Fase } 4 \\
(1,4 \mathrm{TL}) \\
84 \mathrm{~s}\end{array}$ & $\begin{array}{c}\text { Fase } 5 \\
(0,5 \mathrm{TL}) \\
30 \mathrm{~s}\end{array}$ & $\begin{array}{c}\text { Fase } 6 \\
(1,5 \mathrm{TO}) \\
38 \mathrm{~min}\end{array}$ & $\begin{array}{c}\text { Fase } 6 \\
(1,5 \mathrm{TO} 2) \\
38 \mathrm{~min}\end{array}$ & $\begin{array}{l}\text { Fase } 7 \\
(2 \mathrm{TO}) \\
50 \mathrm{~min}\end{array}$ \\
\hline$V_{r}\left(m^{3}\right)$ & 48,1 & 44,5 & 33,8 & 2,8 & 65,6 & 23,0 & 36,1 & 33,8 & 32,1 \\
\hline$V_{p}\left(m^{3}\right)$ & 361,3 & 318,8 & 318,1 & 23,8 & 367,8 & 263,1 & 390,4 & 318,1 & 388,2 \\
\hline$r(\%)$ & 86,7 & 86,0 & 89,4 & 88,1 & 82,2 & 91,3 & 90,7 & 89,4 & 91,7 \\
\hline
\end{tabular}

$\mathrm{V}_{\mathrm{r}}$ : volume de retrolavagem; $\mathrm{V}_{\mathrm{p}}$ : volume do permeado; r: recuperação; Q: vazão; TO: tempo de operação; TL: tempo de limpeza. Fonte: elaborada pelos autores.

Tabela 7 - Qualidade do permeado nas diferentes fases experimentais - valor médio / desvio padrão dos parâmetros analisados.

\begin{tabular}{|c|c|c|c|c|c|c|c|c|c|}
\hline $\begin{array}{l}\text { Parâm. } \\
\text { (mg. } L^{-1} \text { ) }\end{array}$ & $\begin{array}{l}\text { Fase } 1 \\
(P)\end{array}$ & $\begin{array}{l}\text { Fase } 2 \\
(1,5 \mathrm{Q})\end{array}$ & $\begin{array}{l}\text { Fase } 3^{*} \\
(1,25 \mathrm{Q})\end{array}$ & $\begin{array}{l}\text { Fase } 4 \\
(1,4 \mathrm{TL})\end{array}$ & $\begin{array}{l}\text { Fase } 5 \\
(0,5 \mathrm{TL})\end{array}$ & $\begin{array}{l}\text { Fase } 6 \\
(1,5 T O)\end{array}$ & $\begin{array}{c}\text { Fase } 6 \\
\left(1,5 \mathrm{TO}^{2}\right)\end{array}$ & $\begin{array}{l}\text { Fase } 7 \\
(2 \mathrm{TO})\end{array}$ & $\begin{array}{l}\text { Média } \\
\text { UF }\end{array}$ \\
\hline $\mathrm{pH}$ & 7,2 / 0,2 & $7,0 / 0,3$ & 7,0 & 6,7 / 0,1 & $7,0 / 0,2$ & $6,8 / 0,2$ & $6,8 / 0,5$ & $7,1 / 0,1$ & $6,9 / 0,3$ \\
\hline Turb.(UT) & $0,7 / 0,4$ & $0,3 / 0,2$ & 0,2 & 0,3 / 0,1 & $0,3 / 0,2$ & $0,3 / 0,1$ & $0,4 / 0,2$ & $0,3 / 0,2$ & $0,4 / 0,3$ \\
\hline SDT & 355 / 26 & 344 / 81 & 348 & $295 / 59$ & 335 / 6 & $270 / 51$ & 304 / 55 & $283 / 49$ & 319 / 55 \\
\hline SST & $3,5 / 2,5$ & $2,0 / 0,0$ & 2,0 & $2,0 / 0,0$ & $2,4 / 0,7$ & $2,0 / 0,0$ & $2,0 / 0,0$ & $2,0 / 0,0$ & $2,2 / 0,8$ \\
\hline ST & $306 / 9$ & 265 / 27 & 244 & $334 / 5$ & $314 / 10$ & $289 / 28$ & 309 / 23 & 304 / 24 & $300 / 29$ \\
\hline STF & $216 / 3$ & $249 / 34$ & 242 & $223 / 21$ & $193 / 27$ & $211 / 12$ & $253 / 33$ & $224 / 44$ & 227 / 32 \\
\hline STV & $90 / 8$ & $16 / 16$ & 2 & $111 / 16$ & $121 / 32$ & $78 / 28$ & $55 / 39$ & $80 / 26$ & $75 / 36$ \\
\hline DQO & $28,7 /$ * & $27,5 / 3,5$ & 28,2 & $25,1 / 4,3$ & $21,6 / 3,0$ & $18,6 / 4,6$ & $16,1 / 1,6$ & 24,9 / 4,9 & $22,1 / 4,6$ \\
\hline DQOf & 11,4 / * & $15,1 / 1,2$ & 15,5 & $10,4 / 5,0$ & $18,1 / 4,7$ & 16,9 / 4,4 & $15,5 / 2,1$ & 23,9 / 9,2 & 18,7 / 6,6 \\
\hline $\mathrm{NO}_{2}$ & 2,78 / 0,38 & 2,08 / 0,96 & 1,64 & 1,80 / 0,99 & 1,92 / 0,08 & 1,54 / 0,91 & 1,35 / 0,24 & 1,53 / 0,82 & 1,69 / 0,69 \\
\hline $\mathrm{NO}_{3}$ & 1,91 / 0,77 & $3,07 / 1,45$ & 2,26 & $6,75 / 1,99$ & 2,81 / 0,15 & $4,12 / 1,74$ & $2,43 / 1,26$ & 5,18 / 1,66 & 3,93 / 1,78 \\
\hline $\mathrm{NH}_{3}$ & 30,2 / 6,0 & 30,8 / 22,7 & 33,7 & $8,5 / 9,8$ & $21,7 / 4,0$ & $10,3 / 8,9$ & 15,8 / 13,3 & $10,1 / 8,6$ & $18,3 / 13,2$ \\
\hline Pt & $0,26 / 0,37$ & 0,08 / 0,09 & 0,07 & $0,06 / 0,04$ & $0,07 / 0,03$ & $0,04 / 0,01$ & $0,14 / 0,05$ & $0,05 / 0,02$ & 0,09 / 0,12 \\
\hline $\begin{array}{l}\text { Coli. total } \\
\text { NMP/100mL }\end{array}$ & $\begin{array}{c}1,2 \mathrm{E}+\mathrm{O} 2 / \\
1,7 \mathrm{E}+\mathrm{O} 2\end{array}$ & $\begin{array}{c}1, \mathrm{OE}+\mathrm{O} 2 / \\
1,5 \mathrm{E}+\mathrm{O} 2\end{array}$ & $4,9 E+O 1$ & $\begin{array}{l}3,9 \mathrm{E}+\mathrm{O} 1 / \\
9,2 \mathrm{E}+\mathrm{OO}\end{array}$ & $\begin{array}{c}6, \mathrm{OE}+\mathrm{O} 2 / \\
5,3 \mathrm{E}+\mathrm{O} 2\end{array}$ & $\begin{array}{c}3,7 \mathrm{E}+01 / \\
6,2 \mathrm{E}+01\end{array}$ & $\begin{array}{l}1, \mathrm{OE}+\mathrm{O} 3 / \\
\mathrm{n} 6,6 \mathrm{E}+\mathrm{O} 2\end{array}$ & $\begin{array}{c}1,8 \mathrm{E}+\mathrm{OO} / \\
1,3 \mathrm{E}+\mathrm{OO}\end{array}$ & $\begin{array}{r}2, \mathrm{OE}+\mathrm{O} 2 \\
3,9 \mathrm{E}+\mathrm{O} 2\end{array}$ \\
\hline $\begin{array}{l}\text { E. Coli } \\
\text { NMP/100mL }\end{array}$ & $\begin{array}{c}7,4 \mathrm{E}+01 / \\
1,7 \mathrm{E}+02\end{array}$ & $\begin{array}{c}6,2 \mathrm{E}+\mathrm{O} 1 / \\
9,1 \mathrm{E}+\mathrm{O} 1\end{array}$ & $2,9 \mathrm{E}+\mathrm{O}$ & $\begin{array}{l}2,3 E+01 / \\
5,5 E+O O\end{array}$ & $\begin{array}{c}3,6 \mathrm{E}+\mathrm{O} 2 / \\
3,2 \mathrm{E}+\mathrm{O} 2\end{array}$ & $\begin{array}{c}2,2 \mathrm{E}+01 / \\
3,7 \mathrm{E}+01\end{array}$ & $\begin{array}{c}6,2 \mathrm{E}+\mathrm{O} 2 / \\
4, \mathrm{OE}+\mathrm{O} 2\end{array}$ & $\begin{array}{c}1,3 \mathrm{E}+\mathrm{OO} / \\
5,8 \mathrm{E}+\mathrm{O} 1\end{array}$ & $\begin{array}{l}1,3 \mathrm{E}+\mathrm{O} 2 / \\
2,3 \mathrm{E}+\mathrm{O} 2\end{array}$ \\
\hline
\end{tabular}

*Foi realizada apenas uma amostra da Fase 3 e nos parâmetros indicados; SDT: sólidos dissolvidos totais; SST: sólidos suspensos totais; ST: sólidos totais; STF: sólidos totais fixos; STV: sólidos totais voláteis; DQO: demanda química de oxigênio; DQOf: demanda química de oxigênio filtrada; $\mathrm{NO}_{2}$ : nitrito; $\mathrm{NO}_{3}$ : nitrato; $\mathrm{NH}_{3}$ : amônia; Pt: fósforo total; Coli. total: coliformes totais; E. Coli: Escherichia Coli.

Fonte: elaborada pelos autores. 
de UF, particularmente quando é utilizada a coagulação como pré-tratamento da alimentação da membrana (LEE et al.; 2017 \& AMARASIRI et al., 2017), podendo alcançar $4,7 \log$ de remoção. Portanto, o tratamento de efluentes por membrana de UF possui um diferencial com relação à FAD, a elevada remoção de microrganismos patogênicos.
Dessa forma, o processo de UF precedido de coagulação química como pós-tratamento de efluentes da etapa de lodos ativados da ETEB Norte apresentou-se como alternativa promissora de tratamento, produzindo permeado de melhor qualidade do que o efluente da etapa de FAD, com a vantagem adicional de menor variação da qualidade.

\begin{tabular}{|c|c|c|c|c|c|c|c|c|}
\hline Parâm. (\%) & $\begin{array}{l}\text { Fase } 1 \\
(P)\end{array}$ & $\begin{array}{l}\text { Fase } 2 \\
(1,5 \mathrm{Q})\end{array}$ & $\begin{array}{l}\text { Fase } 3 \text { * } \\
(1,25 Q)\end{array}$ & $\begin{array}{l}\text { Fase } 4 \\
(1,4 \mathrm{TL})\end{array}$ & $\begin{array}{c}\text { Fase } 5 \\
(0,5 \mathrm{TL})\end{array}$ & $\begin{array}{c}\text { Fase } 6 \\
(1,5 T O)\end{array}$ & $\begin{array}{l}\text { Fase } 7 \\
(2 \mathrm{TO})\end{array}$ & $\begin{array}{l}\text { Média } \\
\text { UF }\end{array}$ \\
\hline Turb. & $93,6 / 3,6$ & $98,3 / 0,4$ & 98,7 & $96,3 / 2,8$ & $98,7 / 1,0$ & $95,7 / 5,4$ & $95,3 / 0,2$ & $97,1 / 2,6$ \\
\hline SDT & $-5,8 / 2,6$ & $-7,6 / 9,4$ & $-7,1$ & $-3,0 / 2,1$ & $-5,7 / 2,1$ & $-5,1 / 3,3$ & $-0,9 / 3,6$ & $-5,6 / 6,0$ \\
\hline SST & $81,8 / 7,3$ & $96,3 / 2,0$ & 96,9 & $91,8 / 6,1$ & $95,9 / 2,2$ & $95,7 / 2,0$ & $79,4 / 15,7$ & $92,5 / 17,9$ \\
\hline STF & $8,7 / 5,4$ & 10,9/10,9 & 6,9 & $9,9 / 10,3$ & $20,5 / 10,6$ & 0,6/10,3 & $0,6 / 22,4$ & $9, \mathrm{O} / 11,1$ \\
\hline STV & $26,5 / 21,2$ & $68,7 / 30,5$ & 97,2 & $10,3 / 8,2$ & 28,2/17,8 & $37,1 / 21,6$ & 26,1/23,7 & $41,9 / 26,9$ \\
\hline DQO & $61,21^{*}$ & $66,4 / 3,9$ & 66,8 & $55,2 / 14,6$ & $81,5 / 3,8$ & $72,3 / 12,7$ & $56,5 / 32,8$ & $71,8 / 27,0$ \\
\hline DQOf & $-6,9 /^{*}$ & $35,0 / 22,1$ & 44,6 & $62,4 / 16,1$ & $23,0 / 23,0$ & $28,2 / 24,6$ & 31,9/19,3 & 23,9/23,1 \\
\hline Pt & $73,4 / 24,8$ & $94,3 / 6,0$ & 96,9 & $94,7 / 3,1$ & $96,1 / 2,2$ & $95,2 / 3,4$ & 94,2/0,7 & $93,0 / 9,5$ \\
\hline CT (log) & 5,08/1,96 & $4,84 / 1,34$ & 4,40 & $4,2 \mathrm{O} / 0,2$ & 5,53/0,4 & 5,24/1,17 & 3,63/0,68 & $4,66 / 1,05$ \\
\hline E. Coli (log) & $4,96 / 1,79$ & $4,76 / 1,2$ & 4,40 & $4,2 \mathrm{O} / 0,2$ & $5,38 / 0,41$ & $5,09 / 1,05$ & $3,62 / 0,56$ & $4,55 / 0,94$ \\
\hline
\end{tabular}

*Foi realizada apenas uma amostra da fase 3 e nos parâmetros indicados. SDT: sólidos dissolvidos totais; SST: sólidos suspensos totais; ST: sólidos totais; STF: sólidos totais fixos; STV: sólidos totais voláteis; DQO: demanda química de oxigênio; DQOf: demanda química de oxigênio filtrada; $\mathrm{NO}_{2}$ : nitrito; $\mathrm{NO}_{3}$ : nitrato; $\mathrm{NH}_{3}$ : amônia; Pt: fósforo total; $\mathrm{CT}$ : coliformes totais; E. Coli: Escherichia Coli.

Fonte: elaborada pelos autores.

Tabela 9 - Volume de rejeito/lodo pela instalação piloto de ultrafiltração no processo de limpeza física e química.

\begin{tabular}{l|c|c|c|c|c|c|c|c|c} 
& $\begin{array}{c}\text { Fase 1 } \\
(\mathrm{P})\end{array}$ & $\begin{array}{c}\text { Fase 1 } \\
(\mathrm{P} 2)\end{array}$ & $\begin{array}{c}\text { Fase 2 } \\
(1,5 \mathrm{Q})\end{array}$ & $\begin{array}{c}\text { Fase 3 } \\
(1,25 \mathrm{Q})\end{array}$ & $\begin{array}{c}\text { Fase 4 } \\
(1,4 \mathrm{TL})\end{array}$ & $\begin{array}{c}\text { Fase 5 } \\
(\mathbf{0 , 5} \mathrm{TL})\end{array}$ & $\begin{array}{c}\text { Fase 6 } \\
(1,5 \mathrm{TO})\end{array}$ & $\begin{array}{c}\text { Fase 6 } \\
(1,5 \mathrm{TO2})\end{array}$ & $\begin{array}{c}\text { Fase 7 } \\
(2 \mathrm{TO})\end{array}$ \\
\hline $\mathrm{V}_{\mathrm{r}}\left(\mathrm{m}^{3}\right)$ & 48,1 & 44,5 & 33,8 & 2,8 & 65,6 & 23,0 & 36,1 & 33,8 & 32,1 \\
\hline $\mathrm{V}_{\mathrm{d}}\left(\mathrm{m}^{3}\right)$ & 11,0 & 6,4 & 1,7 & 0,6 & 11,2 & 8,2 & 7,8 & 6,4 & 5,9 \\
\hline$V_{\mathrm{e}}\left(\mathrm{m}^{3}\right)$ & 18,1 & 28,9 & 23,4 & 1,9 & 33,0 & 12,8 & 24,3 & 23,4 & 20,7 \\
\hline$V_{p}\left(m^{3}\right)$ & 361,3 & 318,8 & 318,1 & 23,8 & 367,8 & 263,1 & 390,4 & 318,1 & 388,2 \\
\hline$L=V_{r}+V_{d}\left(m^{3}\right)$ & 59,1 & 50,9 & 35,5 & 3,4 & 76,8 & 31,2 & 43,9 & 40,2 & 38,0 \\
\hline$L /\left(V_{p}-V_{p}\right)$ & 0,19 & 0,19 & 0,12 & 0,16 & 0,25 & 0,13 & 0,12 & 0,14 & 0,11 \\
\hline
\end{tabular}

$\mathrm{V}_{\mathrm{r}}$ v volume de retrolavagem; $\mathrm{V}_{\mathrm{d}}$ : volume de drenagem do módulo; $\mathrm{V}_{\mathrm{e}}$ : volume de enxágue; $\mathrm{V}_{\mathrm{p}}$ volume do permeado; $\mathrm{e} \mathrm{L}$ : volume de lodo produzido. Fonte: elaborada pelos autores.

Tabela 10 - Relação entre volume de lodo químico e esgoto tratado produzido na flotação por ar dissolvido da estação de tratamento de esgoto Brasília Norte em 2018.

\begin{tabular}{|c|c|c|c|c|c|c|c|}
\hline Ano 2018 & $\begin{array}{l}\text { Volume de esgoto } \\
\text { tratado } \mathrm{Q}\left(\mathrm{m}^{3}\right)\end{array}$ & $\begin{array}{l}\text { Volume de lodo } \\
\text { químico } L_{Q}\left(m^{3}\right)\end{array}$ & $\begin{array}{l}\text { Volume de lodo } \\
\text { primário } L_{p}\left(m^{3}\right)\end{array}$ & $\begin{array}{l}\text { Volume de lodo } \\
\text { biológico } \mathrm{L}_{\mathrm{B}}\left(\mathrm{m}^{3}\right)\end{array}$ & $\begin{array}{l}\text { Volume total de } \\
\text { lodo } L_{\mathrm{T}}\left(\mathrm{m}^{3}\right)\end{array}$ & $\mathrm{L}_{\mathrm{Q}} /\left(\mathrm{Q}-\mathrm{L}_{\mathrm{Q}}\right)$ & $\mathrm{L}_{\mathrm{T}} /\left(\mathrm{Q}-\mathrm{L}_{\mathrm{Q}}\right)$ \\
\hline Média & 1.361 .293 & 2.992 & 4.938 & 5.726 & 13.655 & 0,0022 & 0,0101 \\
\hline
\end{tabular}

Obs:: a medição de vazão da estação de tratamento é localizada antes da etapa de flotação por ar dissolvido.

Fonte: elaborada pelos autores. 
Tabela 11 - Estatística descritiva das análises realizadas no afluente à flotação por ar dissolvido e instalação piloto de ultrafiltração, efluente da flotação por ar dissolvido, permeado da instalação piloto de ultrafiltração (com todas as fases do experimento) e remoção média da flotação por ar dissolvido e da instalação piloto de ultrafiltração.

\begin{tabular}{|c|c|c|c|c|c|c|c|c|c|c|c|c|c|c|c|}
\hline \multirow{2}{*}{ Parâmetros } & \multirow{2}{*}{$\begin{array}{c}\text { Número } \\
\text { amostras }\end{array}$} & \multicolumn{4}{|c|}{ Afluente à FAD e IP-UF (Af) } & \multicolumn{4}{|c|}{ Efluente da FAD (Ef FAD) } & \multicolumn{4}{|c|}{ Permeado da IP-UF (Ef UF) } & \multicolumn{2}{|c|}{$\begin{array}{l}\text { Remoção } \\
\text { média }\end{array}$} \\
\hline & & Min & Máx & Méd & DP & Mín & Máx & Méd & DP & Mín & Máx & Méd & DP & FAD & IP-UF \\
\hline $\mathrm{pH}$ & 33 & 6,0 & 7,3 & 6,8 & 0,3 & 6,2 & 7,6 & 7,0 & 0,3 & 6,3 & 7,4 & 6,9 & 0,3 & - & - \\
\hline$O D\left(m g . L^{-1}\right)$ & 33 & 2,7 & 4,7 & 3,7 & 0,5 & 3,9 & 6,1 & 5,3 & 0,4 & 2,9 & 5,3 & 4,0 & 0,5 & - & - \\
\hline Turbidez (UT) & 33 & 3,8 & 42,7 & 20,4 & 11,4 & 0,4 & 7,3 & 1,9 & 1,2 & 0,1 & 1,2 & 0,4 & 0,3 & $87,7 \%$ & $97,1 \%$ \\
\hline SDT (mg. $\left.\mathrm{L}^{-1}\right)$ & 33 & 212 & 413 & 303 & 55 & 232 & 421 & 318 & 55 & 221 & 418 & 319 & 55 & $-5,3 \%$ & $-5,6 \%$ \\
\hline $\mathrm{SST}\left(\mathrm{mg} \cdot \mathrm{L}^{-1}\right)$ & 32 & 5 & 139 & 56 & 39 & 4 & 27 & 7 & 4 & 2 & 6 & 2 & 1 & $79,5 \%$ & $92,5 \%$ \\
\hline $\mathrm{ST}\left(\mathrm{mg} \cdot \mathrm{L}^{-1}\right)$ & 22 & 292 & 454 & 368 & 44 & 240 & 362 & 312 & 27 & 242 & 340 & 300 & 29 & $15,4 \%$ & $17,6 \%$ \\
\hline $\operatorname{STF}\left(m g . L^{-1}\right)$ & 31 & 198 & 316 & 251 & 34 & 184 & 296 & 230 & 29 & 174 & 290 & 227 & 32 & $8,0 \%$ & $9,0 \%$ \\
\hline STV $\left(m g . L^{-1}\right)$ & 31 & 36 & 212 & 127 & 41 & 10 & 142 & 86 & 33 & 2 & 144 & 75 & 36 & $31,6 \%$ & $41,9 \%$ \\
\hline DQO (mg. $\left.L^{-1}\right)$ & 29/29/28 & 35 & 174 & 94 & 36 & 21 & 39 & 30 & 5 & 15 & 31 & 22 & 5 & $63,3 \%$ & $71,8 \%$ \\
\hline DQOf (mg.L'-1) & 29 & 16 & 41 & 25 & 6 & 12 & 38 & 21 & 6 & 5 & 35 & 19 & 7 & $14,2 \%$ & $23,9 \%$ \\
\hline $\mathrm{NO}_{2}\left(\mathrm{mg} \cdot \mathrm{L}^{-1}\right)$ & 33 & 0,62 & 3,24 & 1,79 & 0,71 & 0,58 & 3,12 & 1,68 & 0,64 & 0,60 & 3,18 & 1,69 & 0,69 & $4,9 \%$ & $5,5 \%$ \\
\hline $\mathrm{NO}_{3}\left(\mathrm{mg} \cdot \mathrm{L}^{-1}\right)$ & 33 & 1,70 & 8,85 & 4,06 & 1,73 & 1,41 & 8,48 & 4,06 & 1,76 & 1,11 & 8,45 & 3,93 & 1,78 & $0,7 \%$ & $3,9 \%$ \\
\hline $\mathrm{NH}_{3}\left(\mathrm{mg} \cdot \mathrm{L}^{-1}\right)$ & 33 & 0,206 & 47,3 & 17,4 & 12,9 & 0,206 & 43,6 & 18,3 & 13,0 & 0,206 & 46,6 & 18,3 & 13,2 & $-6,5 \%$ & $-10,1 \%$ \\
\hline Pt $\left(m g \cdot L^{-1}\right)$ & 33 & 0,41 & 5,06 & 1,84 & 1,11 & 0,08 & 0,60 & 0,28 & 0,12 & 0,02 & 0,69 & 0,09 & 0,12 & $80,1 \%$ & $93,0 \%$ \\
\hline $\begin{array}{l}\text { Coliformes } \\
\text { totais } \\
(\mathrm{NMP} / 100 \mathrm{~mL})\end{array}$ & 32 & $1,3 E+05$ & $4,2 E+O 6$ & $1,3 \mathrm{E}+06$ & $1,1 \mathrm{E}+06$ & $4,2 E+O 3$ & $1,6 E+06$ & $3,1 E+05$ & $3,9 E+05$ & $1, \mathrm{OE}+\mathrm{OO}$ & 1,7E+O3 & $2, \mathrm{OE}+\mathrm{O} 2$ & $3,9 \mathrm{E}+\mathrm{O} 2$ & 0,93 log & 4,48 log \\
\hline $\begin{array}{l}\text { E. Coli } \\
(\mathrm{NMP} / 100 \mathrm{~mL})\end{array}$ & 32 & $7,7 \mathrm{E}+\mathrm{O} 4$ & $2,4 \mathrm{E}+06$ & $7,8 \mathrm{E}+05$ & $6,3 E+05$ & $2,4 \mathrm{E}+\mathrm{O} 3$ & $9,8 E+05$ & $1,9 E+05$ & 2,3E + O5 & $1, \mathrm{OE}+\mathrm{OO}$ & $1, \mathrm{OE}+\mathrm{O} 3$ & $1,2 \mathrm{E}+\mathrm{O} 2$ & $2,3 E+O 2$ & 0,92 log & 4,39 log \\
\hline
\end{tabular}

Obs.: Em número de amostras, as sequências de três números equivalem respectivamente as amostras de Af, Ef FAD e Ef IP-UF. Legenda: FAD: flotação por ar dissolvido da ETEB Norte; IP-UF: instalação piloto de ultrafiltração; DP: desvio padrão; OD: oxigênio dissolvido; SDT: sólidos dissolvidos totais; SST: sólidos suspensos totais; ST: Sólidos totais; STF: sólidos totais fixos; STV: sólidos totais voláteis; DQO: demanda química de oxigênio; DQOf: demanda química de oxigênio filtrada; $\mathrm{NO}_{2}$ : Nitrito: $\mathrm{NO}_{3}$ : Nitrato; $\mathrm{NH}_{3}$ : $\mathrm{Am}_{\text {mônia, }}$ Pt: fósforo total, E. Coli: Escherichia Coli.

Fonte: elaborada pelos autores.

\section{CONSIDERAÇÕES FINAIS}

A utilização da membrana de UF, precedida de coagulação com sulfato de alumínio, como pós-tratamento de efluentes da etapa de lodos ativados mostrou-se promissora quando comparada como a etapa de FAD. A UF apresentou maior eficiência na remoção para os parâmetros: turbidez, SST, DQO, Pt, coliformes totais e $E$. Coli. Considerando-se os valores médios, o ganho em remoção de turbidez, de SST, de DQO e de Pt foi de, respectivamente, 9,4, $13,0,8,5$ e 12,8\%. Já com relação às bactérias do grupo coliformes, o ganho de 3,4 log ao se comparar a UF com a FAD merece destaque. Por outro lado, tanto a UF quanto a FAD não foram efetivas na remoção da série de nitrogênio e sólidos dissolvidos.

O aumento do fluxo do permeado de 40,25 L.m- ${ }^{2} \cdot \mathrm{h}^{-1}$ para 50,64 e 61,02 L.m- ${ }^{2} \cdot h^{-1}$, o aumento do tempo de operação entre as limpezas de 25 min para 38 e 50 min e a redução da duração da retrolavagem de $80 \mathrm{~s}$ para 60 e 30 s resultaram em evolução mais intensa da PTM, desfavorável para a operação da IP-UF. A recuperação do módulo de membrana variou entre 82,2 e $91,7 \%$ para as diversas alterações das condições operacionais dos experimentos, e a produção relativa de lodo na IP-UF foi elevada, aproximadamente 80 vezes maior que a de lodo químico na FAD e 17 vezes maior que todo o lodo produzido na ETEB Norte. O tratamento e a destinação do resíduo produzido pela UF devem ser equacionados.

\section{AGRADECIMENTOS}

Agradecemos à DOW Water and Process Solutions a cessão da instalação piloto e à Caesb o apoio laboratorial e logístico.

\section{CONTRIBUIÇÃO DOS AUTORES}

Bertolossi, V. M.: Conceituação, Curadoria de Dados, Análise Formal, Metodologia, Investigação, Escrita - Primeira redação. Neder, T. F.: Curadoria de Dados, Metodologia, Investigação, Escrita - Revisão e Edição. Brandão: C. C. S.: Conceituação, Curadoria dos Dados, Metodologia, Supervisão, Escrita Revisão e Edição. 


\section{REFERÊNCIAS}

ABDESSEMED, D.; NEZZAL, G.; AIM, R. B. Treatment of wastewater by ultrafiltration. Desalination, v. 126, n. 1-3, p. 1-5, 1999. http://doi.org/10.1016/ SO011-9164(99)00149-6

ABBT-BRAUN, G.; BRÖNICK, H.; BRANDÃO, C. C. S.; CAVALCANTI, C. B. G.; CAVALCANTI, C. P.; FRIMMEL, F. H.; MAJEWSKY, M.; STEINIGER, B.; TRÖSTER, M.; WORCH, E. Water Quality of tropical reservoirs in a changing world - the case of Lake Paranoá, Brasília, Brazil. In: LORZ, C.; MAKESCHIN, F.; WEISS, H. Integrated Water Resource Management in Brazil. 1a ed. Londres: IWA Publishing, 2014. p. 74-95

ACERO, J. L.; BENITEZ, F. J.; REAL, F. J.; TEVA, F. Micropollutants removal from retentates generated in ultrafiltration and nanofiltration treatments of municipal secondary effluents by means of coagulation, oxidation, and adsorption processes. Chemical Engineering Journal, n. 289, p. 48-58, 2016. http://doi.org/10.1016/j.cej.2015.12.082

APHA; AMERICAN WATER WORKS ASSOCIATION (AWWA); WEF. Standard methods for the examination of water and wastewater. 23a ed. Nova York: LMC - Pharmabooks, 2017

AMARASIRI, M.; KITAJIMA, M.; NGUYEN, T. H.; OKABE, S.; SANO, D. Bacteriophage removal efficiency as a validation and operational monitoring tool for virus reduction in wastewater reclamation: review. Water Research, n. 121, p. 258-269, 2017. https://doi.org/10.1016/j. watres.2017.05.035

ARÉVALO, J.; GARRALÓN, G.; PLAZA, F.; MORENO, B.; PÉREZ, J.; GOOMEZ, M. A. Wastewater reuse after treatment by tertiary ultrafiltration and a membrane bioreactor (MBR): a comparative study. Desalination, v. 243, n. 1-3, p. 32-41, 2009. https://doi.org/10.1016/j.desal.2008.04.013

ARIKA, M.; KOBAYASHI, H.; KIHARA, H. Pilot plant test of an activated sludge ultrafiltration combined process for domestic wastewater reclamation. Desalination, v. 23, n. 1-3, p. 77-86, 1977. https://doi.org/10.1016/s00119164(00)82510-2

CAESB. SIESG - Sinopse do Sistema de Esgotamento Sanitário do Distrito Federal. 27a ed. Brasília: Caesb, 2014, 169 p

CAESB. Planilha de dados operacionais e de qualidade da ETE Brasilia Norte. Brasília: Caesb, 2019

CAESB/SEEBLA. Projeto Básico de Ampliação e Adaptação da ETEB-Norte e ETEB Sul - Memorial Descritivo. Vol. 1, tomo 1. Brasília: SEEBLA, 1982. 137 p.

CITULSKI, J.; FARAHBAKHSH, K.; KENT, F. Optimization of phosphorus removal in secondary effluent using immersed ultrafiltration membranes with in-line coagulant pretreatment - implications for advanced water treatment and reuse applications. Canadian Journal of Civil Engineering, v. 36, n. 7. p. 1272-1283, 2009. https://doi.org/10.1139/L09-062

DIAZ, S. D.; PEÑA, L. V.; CABRERA, E. G.; SOTO, M. M.; CABEZAS, L. M. V.; SANCHEZ, L. R. B. Effect of previous coagulation in direct ultrafiltration of primary settled municipal wastewater. Desalination, v. 304, p. 41-48, 2012. https://doi.org/10.1016/j.desal.2012.08.005

GRAND RESEARCH GROUP. Report overview: membrane separation technology market size, share $\&$ trends analysis report by technology (microfiltration, ultrafiltration, nanofiltration), by application, by region, and segment forecasts, 2020-2027. Disponível em: https://www. grandviewresearch.com/industry-analysis/membrane-separationtechnology-market. Acesso em: 21 out. 2020.

HUYSKENS, C.; WEVER, H. D.; FOVET, Y.; WEGMANN, U.; DIELS, L.; LENAERTS S. Screening of novel MBR fouling reducers: benchmarking with known fouling reducers and evaluation of their mechanism of action. Separation and Purification Technology, v. 95, p. 49-57, 2012. http://doi.org/10.1016/j. seppur.2012.04.024

DOW WATER \& PROCESS SOLUTION. DOW UF Pilot Plant - Handover Documentation. DOW Project no NO-1008-F052. Shanghai, China. 2011. $1207 \mathrm{p}$

LEE, B. B.; CHOO, K. H.; CHANG, D.; CHOI, S. J. Optimizing the coagulant dose to control membrane fouling in combined coagulation/ ultrafiltration systems for textile wastewater reclamation. Chemical Engineering Journal, v. 155, n. 1-2, p. 101-107, 2009. http://doi.org/10.1016/j. cej.2009.07.014

LEE, S.; IHARA, M.; YAMASHITA, N.; TANAKA, H. Improvement of virus removal by pilot-scale coagulation-ultrafiltration process for wastewater reclamation: Effect of optimization of $\mathrm{pH}$ in secondary effluent. Water Research, v. 114, p. 23-30, 2017. https://doi.org/10.1016/j. watres.2017.02.017

LEIKNES, T. Membrane technology in environmental engineeringmeeting future demands and challenges of the water and sanitation sector. Desalination, v. 199, n. 1-3, p. 12-14, 2006. https://doi.org/10.1016/j. desal.2006.03.132

LI, R. H.; WANG, X. M.; LI, X. Y. A membrane bioreactor with iron dosing and acidogenic co-fermentation for enhanced phosphorus removal and recovery in wastewater treatment. Water Research, v. 129, n. 1, p. 402-412, 2018. https://doi.org/10.1016/j.watres.2017.11.035

LY, Q. V.; NGHIEM, L. D.; CHO, J.; HUR, J. Insights into the roles of recently developed coagulants as pretreatment to remove effluent organic matter for membrane fouling mitigation. Journal of Membrane Science, v. 564, p. 643-652, 2018. https://doi.org/10.1016/j.memsci.2018.07.081

METCALF, L.; EDDY, H. P. Tratamento de efluentes e recuperação de recursos. In: McGraw Hill Brasil. 5a ed. Porto Alegre: Ed. AMGHX, 2015. $1980 \mathrm{p}$.

MIERZWA, J. C.; DA SILVA, M. C. C.; VERAS, L. R. V.; SUBTIL, E. L.; RODRIGUES, R.; LI, T.; LANDENBERGER, K. R. Enhancing spiral-wound ultrafiltration performance for direct drinking water treatment through operational procedures improvement: A feasible option for the Sao Paulo Metropolitan Region. Desalination, v. 307, p. 68-75, 2012. https://doi.org/10.1016/j. desal.2012.09.006

RAGIO, R. A.; MIYAZAKI, L. F; OLIVEIRA, M. A.; COELHO, L. H. G.; FREITAS BUENO, R.; SUBTIL, E. L. Pre-coagulation assisted ultrafiltration membrane process for anaerobic effluent. Journal of Environmental Chemical Engineering, v. 8, n. 5, 104066, 2020. https://doi.org/10.1016/j. jece.2020.104066

SHON, H. K.; VIGNESWARAN, S.; KIM, I. S.; CHO, J.; NGO, H. H. Effect of pretreatment on the fouling of membranes: application in biologically treated sewage effluent. Journal of Membrane Science, v. 234, n. 1-2, p. 111 120, 2004. http://doi.org/10.1016/j.memsci.2004.01.015 
VEDAVYASAN C.V. Chemical Cleaning of Membranes. In: DRIOLI, E.; GIORNO, L. (Eds). Encyclopedia of Membranes. Springer, Berlin: Heidelberg, 2016.

YOON, S. H. Membrane bioreactor processes: principles and applications. $1^{\mathrm{a}}$ ed. Boca Raton: Ed. CRC press, 2015. 431 p.

ZHAO, Y.X: LI,P.: LI, R. H.: LI,X.Y. Direct filtration for the treatment of the coagulated domestic sewage using flat-sheet ceramic membranes. Chemosphere, v. 223, p. 383-390, 2019. https://doi.org/10.1016/j.chemosphere.2019.02.055
ZHENG, X.; ERNST, M.; JEKEL, M. Identification and quantification of major organic foulants in treated domestic wastewater affecting filterability in dead-end ultrafiltration. Water Research, v. 43, n. 1, p. 238-244, 2008. https:// doi.org/10.1016/j.watres.2008.10.011

ZHENG, X.; PLUME, S.; ERNST, M.; CROUÉ, J. P.; JEKEL, M. In-line coagulation prior to UF of treated domestic wastewater-foulants removal, fouling control and phosphorus removal. Journal of Membrane Science, v. 403, p. 129-139, 2012. http://doi.org/10.1016/j.memsci.2012.02.051 